\title{
Rehabilitation and Psycho-Social Nursing in a Child with Cerebral Palsy after Patellar Ligament Advancement
}

\author{
Xiaomei Liao ${ }^{1}$, Nianjin Gao ${ }^{1}$, Yan $\mathrm{Li}^{1}$, Shanshan $\mathrm{Luo}^{1}$ and Xiaowen $\mathrm{Zhu}^{2 *}$ \\ ${ }^{1}$ Guangdong 999 Brain Hospital, China \\ ${ }^{2}$ School of Nursing, Jinan University, China
}

*Corresponding author: Xiaowen Zhu, School of Nursing, Jinan University, China

ARTICLE INFO

Received: 幽 May 29, 2019

Published: 幽 June 12, 2019

\section{ABSTRACT}

Abbreviations: SPR : Selective Posterior Rhizotomy; PT: Physical Therapy; TCM: Traditional Chinese Medicine; EEG : Electro Encephalographic

Citation: Nianjin Gao, Xiaomei Liao, Yan Li1, Shanshan Luo, Xiaowen Zhu. Rehabilitation and Psycho-Social Nursing in a Child with Cerebral Palsy after Patellar Ligament Advancement. Biomed J Sci \& Tech Res 18(5)-2019. BJSTR. MS.ID.003206.

\section{Introduction}

Patellar ligament advancement is also known as patellar operative correction. Surgeons cut open the tibial tubercle, move the patella to the position of the tibial tubercle, and then move down tibial tubercle. This operation helps to relax the patellar ligament and stretch the lower limb [1]. We present a youth in crouched gait with cerebral palsy given patellar ligament advancement. This case highlights the need to perform comprehensive rehabilitation assessment and psychosocial nursing on children with cerebral palsy after surgery.

\section{Case Report}

A Chinese male was born premature of gestation by normal vaginal delivery in 2002. His mother suffered from vaginal bleeding at 30 weeks. Then she went to hospital to give birth to a male baby weight nearly but no more than $2 \mathrm{~kg}$ naturally after using oxytocin. The baby was gradually been found that his motor function development was slower than other children of the same age. He can neither sit up straight nor keep head up at seven months. He didn't stand until he was 2 years old. Lumbar selective posterior rhizotomy (SPR) repair of spinal dura mater was performed in a hospital in Guangzhou, China in 2005. After that, his scissors gait was improved. In April 1st, 2017, right patellar ligament advancement, right peroneus longus muscle transposition, and plaster fixation were performed to this boy in our hospital. He came to our hospital for the first course of rehabilitation training after surgery in September $15^{\text {th }}, 2017$. In November $3^{\text {rd }}, 2017$, he was still unable to stand or walk alone. So he admitted to our hospital for the second course of rehabilitation training for 4 weeks.

On limb function physical examination, we found that his hands can grasp, but the fine motor function of fingers was not well. When he was in supine position, he lifted his left leg with slightly bent while right leg was straighter than the left one. When he was assisted to stand, his left knee was in crouched position. We also assessed the Barthel index, muscle strength and muscle tension, pain, anxiety, and fall risk for him. After comprehensive assessment, we found that the primary nursing issues for this patient were dyskinesia and anxiety. For dyskinesia, different types of rehabilitation treatments were performed. Theses treatments including physical therapy (PT), MOTOmed, acupuncture of traditional Chinese medicine (TCM) and Electro encephalographic (EEG) biofeedback therapy. 
During all the rehabilitation training, nurses first explain the current functional status, objectives, and precautions to patient and his family. Then nurses educated them that training should be done gradually to avoid fatigue and injury and should be paid enough attention to safety. Rehabilitation nursing training was ought to be practiced in the ward twice a day. These training including resistance training and active motion, for example isotonic contraction and isometric contraction. Arch bridge movement and shell movement (see in Figure 1 were also recommend to the patient ten times in each group. Center of gravity transfer was also instructed as no more than 15 minutes at a time. After a week's rehabilitation nursing training, the patient can transfer his weight and stand on his own. From that on, stand training was taught to the patient for at least 4 days until he can walk with the aid of a walker at November $16^{\text {th }}$. Walking training was applied since then. The patient can walk on his own at November $22^{\text {nd }}$.

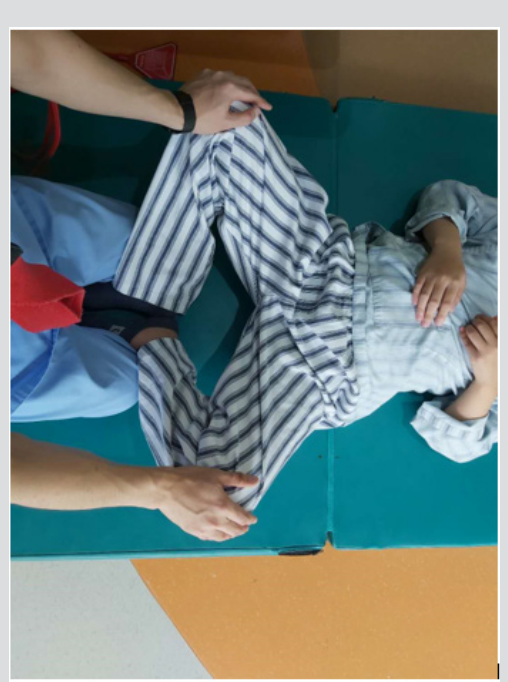

Figure 1: Shell movement.

Before discharge, he can walk around the ward independently. Anxiety for this patient was inferred to mainly associated with postoperative pain, worrying about fall, and his low confidence. So the nursing goal was to reduce his worry and fear. The first nursing intervention for patient's anxiety was to take time to listen. Besides, professional rehabilitation and nursing knowledge should be taught to patient and family at the proper time to eliminate their psychological concerns. To this patient, the main issue of health education should be lied in explaining the current situation after operation. Enlightening to change his cognition was also important. And nurses also pay attention to increase his confidence and maintain his self-esteem. The last but not least nursing intervention was to improve patient's social support systems. The patient discharged at November $29^{\text {th }}, 2017$. The discharge planning including not only rehabilitation training but also participation in social activities and his parents' accompany.

\section{Discussion}

This case suggests the important nursing role in post operation rehabilitation, especially in China, where there is still a gap of hundreds of thousands of rehabilitation therapists. During rehabilitation training, nurses need not only to be familiar with the operation, but also to evaluate comprehensively and systematically [2,3]. Rehabilitation is a long-term work that requires the participation of children, parents, doctors, nurses, and rehabilitation therapists [4]. Nursing interventions should focus in patients' developing rehabilitation needs. In this process, health-care providers' actively driving of parents and children to participate could help the rehabilitation be more smoothly. In rehabilitation training process, psycho-social nursing also plays an important role [5,6]. In psycho-social nursing, listen was the first crucial step to make good communication to promote trust between nurse and patient [7]. Nurses could help patient to change his attitude towards disease and treatment from passive to active. In this case, nurses set up an example that a 15-year-old girl who had surgery one day later than him but could stand alone at the first rehabilitation course. When the patient presented low confidence in his hanging head, nurses praise his appearance and increase his confidence in his self-image. In all these psycho-social education, patient's anxiety released.

\section{Funding}

This research was funded by Guangdong provincial health and family planning commission medical research fund (Grant No. A2017263), Xiaowen ZHU, PI.

\section{References}

1. Taylor D, Connor J, Church C, Lennon N, Henley J, et al. (2016) The effectiveness of posterior knee capsulotomies and knee extension osteotomies in crouched gait in chilfen with cerebral palsy. Journal of Pediatric Orthopaedics B 25(6): 543-550.

2. Boyer ER, Stout JL, Laine JC, Gutknecht SM, Oliveira LH, et al. (2017) Evidence of knee extensor dysfuction during sit-to-stand following distal femoral extension osteotomy and patellar tendon advancement in young adults with cerebral palsy: A pilot study. Gait \& Posture 58: 527-532.

3. Bittmann MF Lenhart RL, Schwartz MH, Novacheck TF, Hetzel S, et al. (2018) How does Patellar Tendon Advancement alter the Knee Extensor Mechanism in Children Treated for Crouch Gait? Gait \& Posture. 64: 248254.

4. Milicevic M (2019) Home participation of children with and without cerebral palsy in Serbia: An exploratory study. Disability and Rehabilitation.

5. Lindsay S (2016) Child and youth experiences and perspectives of cerebral palsy: A qualitative systematic review. Child Care Health and Development 42(2): 153-175.

6. Chiluba BC, Moyo G (2017) Caring for a cerebral palsy child: A caregivers perspective at the University Teaching Hospital, Zambia. BMC Res Notes 10(1): 724-731.

7. Boyer ER, Stout JL, Laine JC, Gutknecht SM, De Oliveira, et al. (2018) Long-term outcomes of distal femoral extension osteotomy and patellar tendon advancement in individuals with cerebral palsy. The Journal of Bone and Joint Surgery 100(1): 31-41. 


\section{ISSN: 2574-1241}

DOI: 10.26717/BJSTR.2019.18.003206

Xiaowen Zhu. Biomed J Sci \& Tech Res

(C) (P) This work is licensed under Creative

Submission Link: https://biomedres.us/submit-manuscript.php

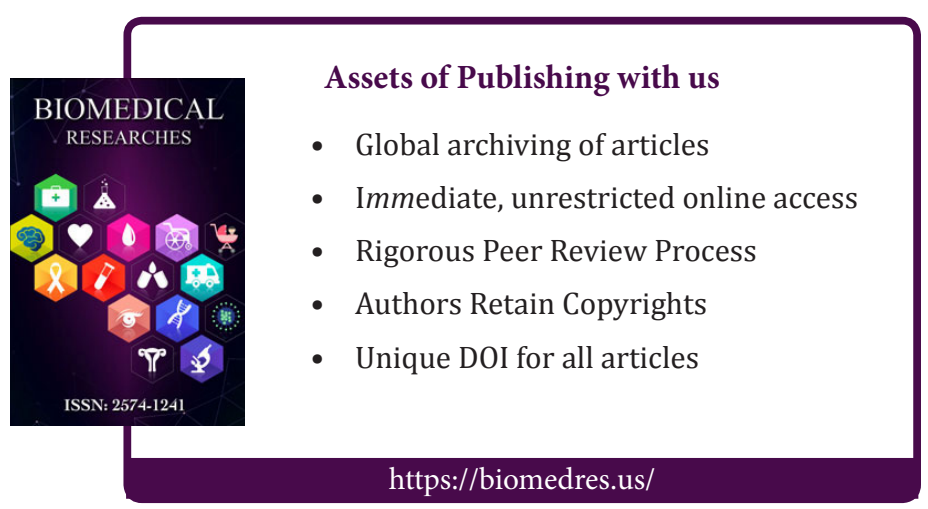

